\title{
Niclosamide enhances the cytotoxic effect of cisplatin in cisplatin-resistant human lung cancer cells via suppression of lung resistance-related protein and c-myc
}

\author{
YUFANG ZUO*, DONGYAN YANG* , YIN YU*, MEI XIANG, HAIWEN LI, JUN YANG, \\ JINGJING LI, DANXIAN JIANG, HECHAO ZHOU, ZUMIN XU and ZHONGHUA YU \\ Cancer Center, Affiliated Hospital of Guangdong Medical University, Zhanjiang, Guangdong 524000, P.R. China
}

Received December 8, 2016; Accepted August 11, 2017

DOI: $10.3892 / \mathrm{mmr} .2017 .8301$

\begin{abstract}
Lung cancer is a leading cause of cancer-associated mortality worldwide. The cisplatin (DDP)-based chemotherapy remains the foundation of treatment for the majority of patients affected by advanced non-small cell lung cancer (NSCLC). However, DDP-resistance limits the clinical utility of this drug in patients with advanced NSCLC. The aim of the present study was to investigate the inhibitory effect of niclosamide on human lung cancer cell growth and to investigate the possible underlying mechanism. The effects of niclosamide on the proliferation of human lung adenocarcinoma (A549) and DDP-resistant (CR) human lung adenocarcinoma (A549/DDP) cells were examined by Cell Counting kit- 8 assay. The impact of niclosamide on the apoptosis of A549/DDP cells was detected by Annexin V-fluorescein isothiocyanate/propidium iodide assay. The expression levels of cisplatin-resistant-associated molecules (lung resistance-related protein and c-myc) following niclosamide treatment in A549/DDP cells were evaluated by western blot analysis. The results indicated that niclosamide in combination with DDP demonstrated a synergistic effect in A549/DDP cells and directly induced apoptosis, which may be associated with caspase-3 activation. Furthermore, niclosamide decreased the expression level of c-myc protein, which may influence DDP sensitivity of A549/DDP cells. Thus, the present study indicates that niclosamide combined with DDP exerts a synergistic effect in cisplatin-resistant lung cancer cells and may present as a promising drug candidate in lung cancer therapy.
\end{abstract}

Correspondence to: Dr Zhonghua Yu or Dr Zumin Xu, Cancer Center, Affiliated Hospital of Guangdong Medical University, 57 South Renmin Road, Zhanjiang, Guangdong 524000, P.R. China E-mail: zhonghua_yu@126.com

E-mail: zuminxu@163.com

*Contributed equally

Key words: niclosamide, non-small cell lung cancer, cisplatin-resistant lung cancer, lung resistance-related protein, c-myc

\section{Introduction}

Lung cancer remains one of the most common types of fatal malignancy. Non-small cell lung cancer (NSCLC), characterized by its high incidence, is the leading cause of cancer-associated mortality worldwide (1). NSCLC accounts for approximately $80-85 \%$ of all lung cancer cases (2) and the majority of patients are diagnosed with local advanced or metastatic disease (3). Although the epidermal growth factor receptor-tyrosine kinase inhibitors (EGFR-TKIs) are recommended as first-line treatment for patients whose tumors harbor activating EGFR mutations (4), platinum-based, double-agent chemotherapy represents the standard of care for unselected patients with advanced NSCLC (5). Cisplatin (DDP) is a commonly used drug with a high curative effect on lung cancer (6). However, in chemotherapy-treated NSCLC, the duration of response is relatively short due to primary or acquired resistance to chemotherapy $(7,8)$. Therefore, it is considered to be urgent to improve the efficacy of DDP-based chemotherapy and to develop novel treatment strategies to overcome DDP resistance for advanced NSCLC.

Niclosamide, a teniacide in the anthelmintic family, which is particularly effective against cestodes, has been approved for use in humans for many years (9). A recent study reported that niclosamide was a multi-functional agent, performing anti-obesity (10), anti-diabetic (11), anti-viral $(12,13)$ and anti-sclerotic (14) activities. Additionally, niclosamide has been identified as a potent anticancer agent using various high-throughput screening assays (15). Niclosamide inhibits the Wnt/ $\beta$-catenin, mammalian target of rapamycin complex 1, signal transducer and activator of transcription 3 (STAT3), nuclear factor- $\kappa \mathrm{B}$ and Notch signaling pathways, and targets mitochondria in cancer cells to induce cell cycle arrest, growth inhibition and apoptosis. A host of studies have established the anticancer activities of niclosamide in in vitro and in vivo models. Furthermore, Li et al (16) identified that niclosamide overcame acquired resistance to erlotinib via suppression of STAT3 in NSCLC. Liu et al (17) demonstrated that niclosamide alone or in combination with DDP significantly inhibited MDA-MB-231/DDP-sensitive (CS) and MDA-MB-231-DDP-resistant (CR) cell 
proliferation in vitro. However, the effect of niclosamide on cisplatin-resistant human lung cancer cells remains unknown.

In the present study, whether niclosamide could enhance the cytotoxic effects of DDP in cisplatin-resistant A549/DDP lung cancer cells was investigated, and the underlying mechanisms were evaluated further.

\section{Materials and methods}

Cell culture. Human A549 lung carcinoma cells and cisplatin-resistant human A549/DDP lung carcinoma cells were purchased from the Type Culture Collection of the Chinese Academy of Sciences (Shanghai, China) and cultured in GibcoRPMI-1640 medium (Thermo Fisher Scientific, Inc, Waltham, MA, USA), supplemented with $10 \%(\mathrm{v} / \mathrm{v})$ dialyzed heat-inactivated bovine serum (Gibco; Thermo Fisher Scientific, Inc.), $100 \mathrm{U} / \mathrm{ml}$ penicillin and $100 \mu \mathrm{g} / \mathrm{ml}$ streptomycin at $37^{\circ} \mathrm{C}$ in $5 \% \mathrm{CO}_{2}$.

Cell viability assay. Cell viability was determined using the Cell Counting kit-8 (CCK-8) assay (Dojindo Molecular Technologies, Inc., Kumamoto, Japan). CCK-8 allows very convenient assays by utilizing Dojindo's highly water-soluble tetrazolium salt. WST-8 [2-(2-methoxy-4-nitrophenyl)-3-(4 -nitrophenyl)-5-(2,4-disulfophenyl)-2H-tetrazolium, monosodium salt] produces a water-soluble formazan dye upon reduction in the presence of an electron carrier. CCK- 8 allows sensitive colorimetric assays for the determination of the number of viable cells in cell proliferation and cytotoxicity assays. WST- 8 is reduced by dehydrogenases in cells to give an orange colored product (formazan), which is soluble in the tissue culture medium. The quantity of formazan dye generated by the activity of dehydrogenases in cells is directly proportional to the number of living cells. Briefly, cells in the early log phase were trypsinized and plated in 96-well plate at a density of $5 \times 10^{3}$ cells per well. Cells were treated with various concentrations of niclosamide (Sigma-Aldrich; Merck KGa, Darmstadt, Germany) and DDP (Haosen Medicine Corp., Liangyungang, China) for $24 \mathrm{~h}$ at $37^{\circ} \mathrm{C}$. Cell density was measured using the CCK-8 assay according to the manufacturer's instructions. The absorbance of each well was determined at a wavelength of $450 \mathrm{~nm}$ using a microplate reader (Thermo Electron Corp., Shanghai, China). The inhibition rate was calculated as follows: Inhibition rate $(\%)=[1-(\mathrm{T}-\mathrm{B}) /(\mathrm{U}-\mathrm{B})] \times 100 \%$; where $\mathrm{T}$ is the treated cell absorbance, $\mathrm{U}$ is the untreated cell absorbance and $\mathrm{B}$ is the background absorbance when neither drug nor CCK-8 was added. All experiments were repeated at least three times independently.

Combination index (CI) analysis. To evaluate whether the antitumor effects of niclosamide combined with DDP were synergistic, additive or antagonistic, combination index (CI) value for drug synergy was calculated using the CompuSyn software (Version 2.1, ComboSyn, Inc., Paramus, NJ, USA) as previously described (14). Using data obtained from CCK-8 assays and CompuSyn software, the dose-effect curves for single agents and their combinations were generated, and the CI values for each dose and the corresponding effect level, referred to as the fraction affected $(\mathrm{Fa}$; the fraction of cells inhibited following drug exposure, for example 0.5 when cell growth is inhibited by $50 \%$ ), were calculated. CI values $<1$ indicated a synergistic effect, values equal to 1 indicated an additive effect and values $>1$ indicated an antagonistic effect. Then, to provide a visual illustration of drug interactions, the $\mathrm{Fa}-\mathrm{CI}$ plot was constructed by simulating CI values over a range of Fa levels from 0.1 to $0.95(18,19)$.

Analysis of apoptosis by Annexin V/propidium iodide (PI) staining. Apoptosis was assessed by Annexin V/PI detection as described previously (20). The A549/DDP cells were plated at a density of $1 \times 10^{5}$ cells per well in six-well plates. The next day, cells were treated with DDP $(5 \mu \mathrm{g} / \mathrm{ml})$, niclosamide $(1 \mu \mathrm{M})$ or cisplatin $(5 \mu \mathrm{g} / \mathrm{ml})$ combined with niclosamide $(1 \mu \mathrm{M})$ for $36 \mathrm{~h}$. The cells were harvested, and washed three times with phosphate-buffered saline (PBS) at $4^{\circ} \mathrm{C}$. Cells were then incubated with $5 \mu \mathrm{l}$ Annexin V-fluorescein isothiocyanate for $3 \mathrm{~min}$ and with $20 \mathrm{ng} / \mathrm{ml} \mathrm{PI}$ in the dark for $15 \mathrm{~min}$. The suspension was then analyzed by flow cytometry (BD Biosciences, San Jose, CA, USA). All data were collected and analyzed by FACSDiva version 6.1.3 (BD Biosciences). The experiments were repeated three times independently and the results were presented as the mean \pm standard deviation.

Western blot analysis. Subsequent to treatments, the cells were collected and lysed. Lysis buffer [20 mM Tris (pH 7.5), $150 \mathrm{mM} \mathrm{NaCl}, 1 \%$ Triton X-100, sodium pyrophosphate, $\beta$-glycerophosphate, EDTA, $\mathrm{Na}_{3} \mathrm{VO}_{4}$ and leupeptin was purchased from Beyotime Institute of Biotechnology (Shanghai, China). Total protein $(\sim 20 \mu \mathrm{g})$ was separated on a $12 \%$ sodium dodecyl sulfate polyacrylamide gel electrophoresis gel and transferred to a polyvinylidene fluoride membrane. After blocking with $5 \%$ non-fat milk in PBS $+0.1 \%$ Tween- 20 for $1 \mathrm{~h}$, the membrane was incubated with the appropriate primary antibody: Anti-caspase-3 (\#14220; Cell Signaling Technology, Inc., Danvers, MA, USA), anti-LRP (sc-23916; 1:1,000; Santa Cruz Biotechnology, Inc., Dallas, TX, USA), anti-c-myc (D84C12, 1:1,000; Cell Signaling Technology, Inc.) and anti- $\beta$-tubulin (AT819, 1:2,000; Beyotime Institute of Biotechnology) overnight at $4^{\circ} \mathrm{C}$. After washing with PBS three times $(10 \mathrm{~min}$ each), the membrane was incubated with goat anti-rabbit (A0208; 1:2,000; Beyotime Institute of Biotechnology) or anti-mouse (A0216; 1:2,000; Beyotime Institute of Biotechnology) IgG-horseradish peroxidase-conjugated secondary antibody for $1 \mathrm{~h}$ at room temperature and washed with PBS three times. The ECL system (Applygen Technologies, Inc., Beijing, China) was used to detect blotting signals according to the manufacturer's instructions. Detection of $\beta$-tubulin served as a loading control.

Statistical analysis. Continuous data are expressed as the mean \pm standard deviation. For two-group comparison, the Student's t-test method was used. SPSS 13.0 software was used to perform all statistical analyses (SPSS, Inc., Chicago, IL, USA). For more than two-group comparison, one-way ANOVA was used. $\mathrm{P}<0.05$ was considered to indicate a statistically significant difference. 


\section{Results}

Niclosamide inhibits the growth of A549 and A549/DDP cells. In order to confirm the differential sensitivity of A549 and its derivative cisplatin-resistant cell line, A549/DDP, to DDP, cells were treated with different concentrations of DDP as indicated for $24 \mathrm{~h}$, and cell viability was measured by CCK-8 assay. $\mathrm{IC}_{50}$ values were calculated using GraphPad Prism 5.0 (GraphPad Software Inc., La Jolla, CA, USA). The data demonstrated that the $\mathrm{IC}_{50}$ values of DDP in A549 and A549/DDP cells were $6.81 \pm 0.78$ and $32.5 \pm 0.21 \mu \mathrm{g} / \mathrm{ml}$, respectively (Fig. 1). The resistance index of A549/DDP cells to DDP was the $\mathrm{IC}_{50}$ of A549/DDP cells divided by $\mathrm{IC}_{50}$ of the A549 cells or $32.5 / 6.81 \mu \mathrm{g} / \mathrm{ml}=4.77$. These data demonstrate that the A549/DDP cell line has a certain resistance to DDP, which is suitable for drug resistance study.

The A549 and A549/DDP cells were treated with various concentrations of niclosamide as indicated $(0,0.125,0.25,0.5$, $1.0,2.0$ and $4.0 \mu \mathrm{M}$ ) for $24 \mathrm{~h}$. Cell viability was measured using CCK-8 assay. The current results demonstrated that niclosamide significantly suppressed cell growth in a dose-dependent manner in A549 and A549/DDP cells (Fig. 2; $\mathrm{P}<0.05)$. The $\mathrm{IC}_{50}$ values after $24 \mathrm{~h}$ of niclosamide in the A549 and A549/DDP cells were $2.60 \pm 0.21$ and $1.15 \pm 0.18 \mu \mathrm{M}$, respectively. Niclosamide appears to exert a markedly greater inhibitory effect on A549/DDP cells when compared with parental A549 cells.

Niclosamide enhances the inhibitory effect of DDP on A549/DDP cells. To examine whether niclosamide combined with DDP exhibits enhanced antitumor effects in cisplatin-resistant lung cancer, A549/DDP cells were treated with 0.5 or $1 \mu \mathrm{M}$ niclosamide along with $1.25,2.5,5,10$ or $20 \mu \mathrm{g} / \mathrm{ml}$ DDP for $24 \mathrm{~h}$. The niclosamide-treated cells demonstrated increased sensitivity to DDP at all concentrations (Fig. 3; $\mathrm{P}<0.05$ ). According to the combined index calculated with CompuSyn software, the CI value of DDP in combination with niclosamide was $<1$, indicating that DDP combined with niclosamide exerts a synergistic effect on A549/DDP cells (Fig. 4).

Niclosamide combined with DDP enhances the apoptosis of A549/DDP cells. Subsequently, the apoptosis of A549/DDP cells after niclosamide $(1 \mu \mathrm{M})$ and DDP $(5 \mu \mathrm{g} / \mathrm{ml})$ treatment was evaluated using flow cytometry. Apoptotic cells were detected following treatment with $1 \mu \mathrm{M}$ niclosamide and/or $5 \mu \mathrm{g} / \mathrm{ml}$ DDP for $36 \mathrm{~h}$. Annexin V/PI analysis indicated that the apoptotic ratios of the control group, niclosamide, DDP and combined treatment group in the A549/DDP cells were $8.36 \pm 1.05,11.0 \pm 3.18,16.5 \pm 5.25$ and $30.36 \pm 4.36 \%$, respectively (Fig. 5A and B). The current data demonstrated that niclosamide in combination with DDP significantly enhanced the tumor killing effect by inducing apoptosis. Furthermore, western blotting was used to detect the activation of caspase-3 protein in A549/DDP cells after the same treatment. The cleavage of caspase-3 was observed to be markedly increased in the combined treatment group compared with the mono-treatment group (Fig. 5C). Therefore, the current results indicate that niclosamide combined with DDP may enhance cytotoxic effects by inducing apoptosis in A549/DDP cells.

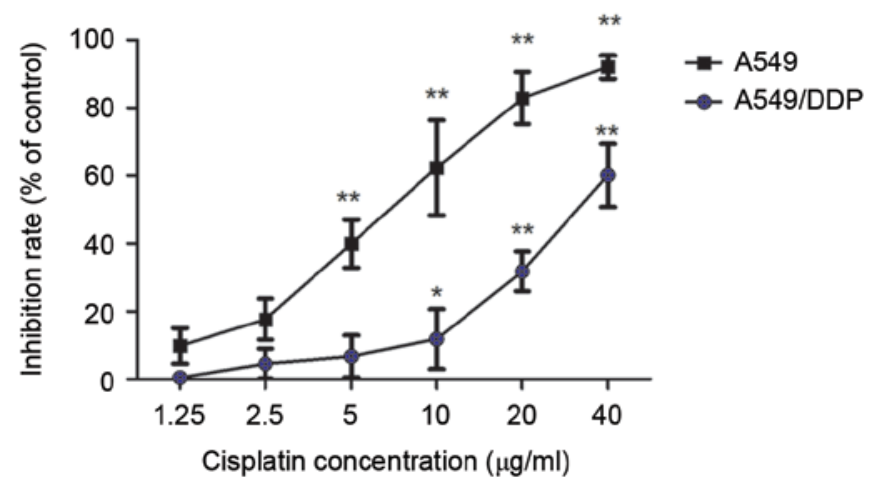

Figure 1. Inhibitory effect of cisplatin on the growth of A549 and A549/DDP cells. Cell viability, as assessed by Cell Counting kit- 8 assay, was determined $24 \mathrm{~h}$ after exposure of A549 or A549/DDP cells to increasing quantities of DDP. Results represent the mean of triplicate wells and are representative of three independent experiments. ${ }^{*} \mathrm{P}<0.05$ and ${ }^{* *} \mathrm{P}<0.01$ vs. control group. DDP, cisplatin; A549, human lung adenocarcinoma cells; A549/DDP, DDP-resistant human lung adenocarcinoma cells.

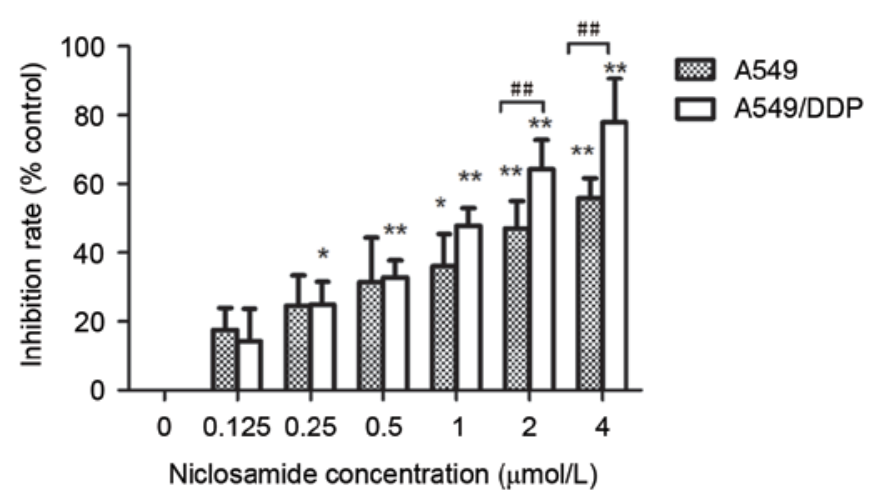

Figure 2. Inhibitory effect of niclosamide on the growth of A549 and A549/DDP cells. A549 or A549/DDP cells were treated with increasing concentrations of niclosamide as indicated for $24 \mathrm{~h}$, and examined by Cell Counting kit- 8 assay. Viability was normalized to $100 \%$ at time zero. Results represent the mean of triplicate wells and are representative of three independent experiments. ${ }^{*} \mathrm{P}<0.05$ and ${ }^{* *} \mathrm{P}<0.01$ vs. control group; ${ }^{\# \#} \mathrm{P}<0.01, \mathrm{~A} 549$ vs. A549/DDP group. DDP, cisplatin; A549, human lung adenocarcinoma cells; A549/DDP, DDP-resistant human lung adenocarcinoma cells.

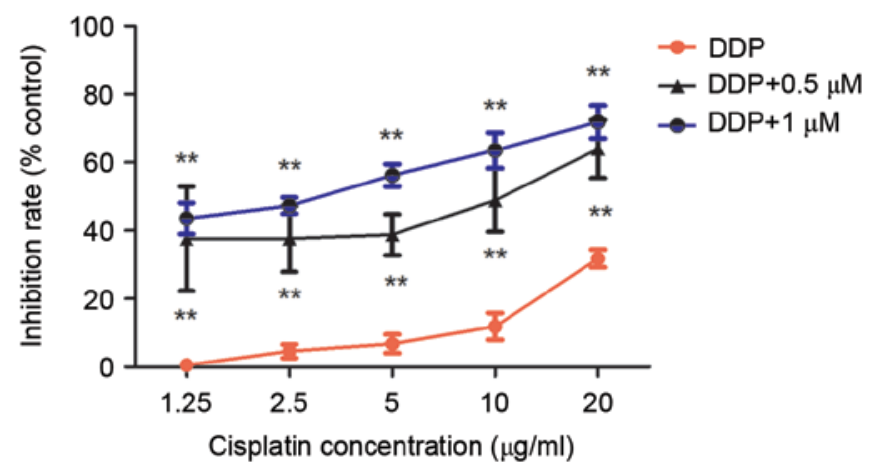

Figure 3. Effect of niclosamide combined with DDP on the proliferation of A549/DDP cells. Proliferation inhibition was determined by Cell Counting kit- 8 assays $24 \mathrm{~h}$ after exposure to a range of concentrations of DDP and 0.5 or $1.0 \mu \mathrm{mol} / 1$ niclosamide plus a range of concentrations of DDP. The inhibition rate of the combined treatment increased markedly at $24 \mathrm{~h}$ compared with DDP alone. Results represent the mean of three experiments performed in triplicate. ${ }^{*} \mathrm{P}<0.05$ and ${ }^{* *} \mathrm{P}<0.01$ vs. DDP alone group. DDP, cisplatin; A549, human lung adenocarcinoma cells; A549/DDP, DDP-resistant human lung adenocarcinoma cells. 

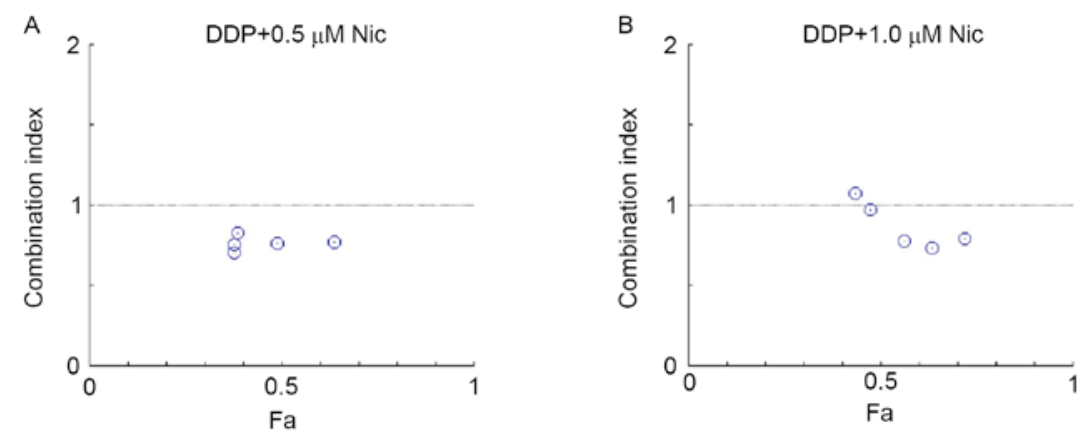

Figure 4. Synergistic effect of A549/DDP cells treated with niclosamide in combination with DDP. A549/DDP cells were treated with either (A) 0.5 or (B) $1.0 \mu \mathrm{mol} / 1$ niclosamide in combination with a range of concentrations of DDP and the synergistic effects were observed in the two groups as calculated by the combination index values $(<1)$. Fa, fraction affected; Nic, niclosamide.
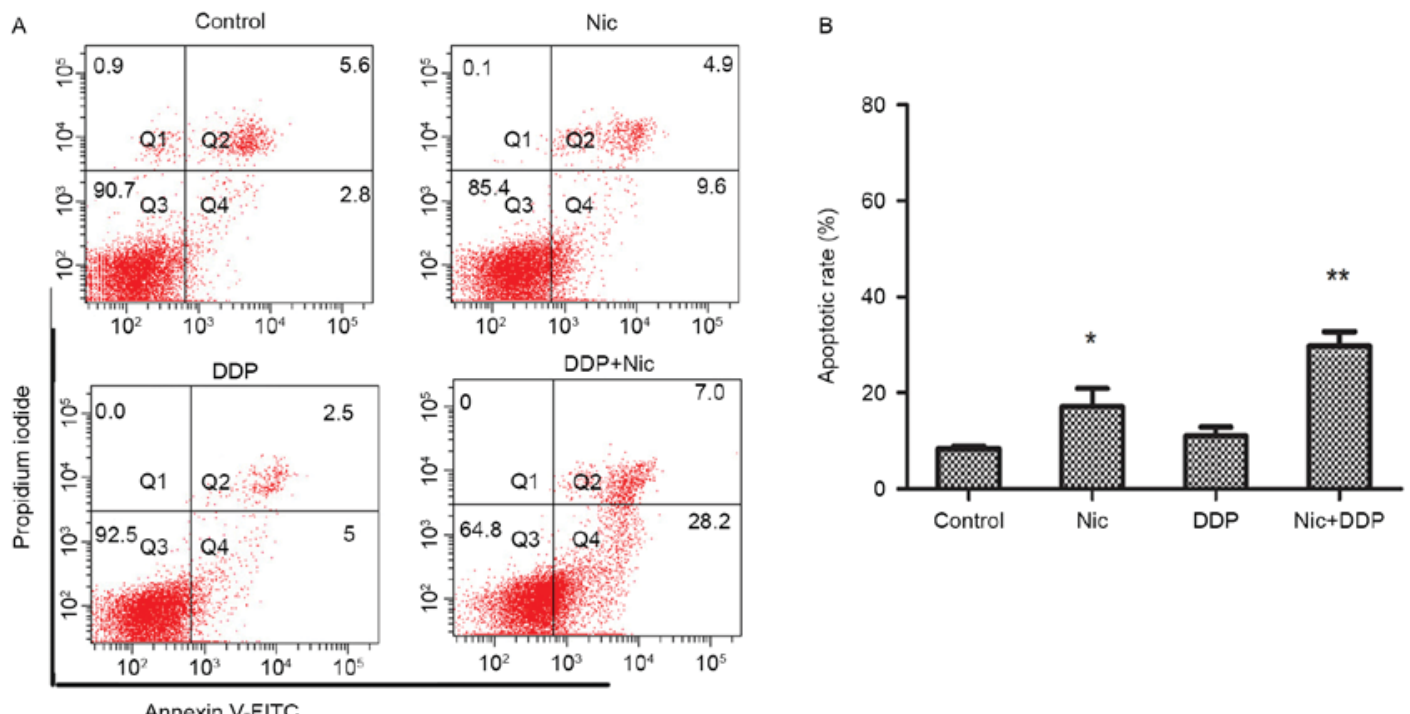

Annexin V-FITC

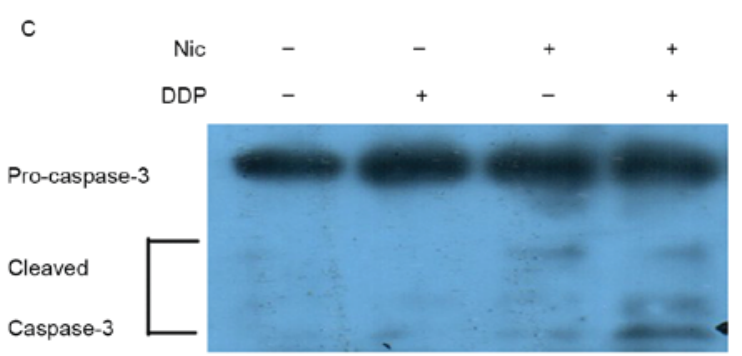

Figure 5. Combination treatment of niclosamide and cisplatin results in an enhancement of apoptosis in A549/DDP cells. (A) A549/DDP cells were treated with niclosamide $(1.0 \mu \mathrm{M})$ or DDP alone, or combined with niclosamide $(1.0 \mu \mathrm{M})$ and DDP $(5 \mu \mathrm{g} / \mathrm{ml})$ for $36 \mathrm{~h}$, the apoptotic cells were determined by flow cytometry. (B) The expression levels of cleaved caspase-3 were determined by western blotting. (C) Cleavage of caspase-3 proteins in A549/DDP cells treated with niclosamide and DDP was markedly increased compared with niclosamide or DDP alone $(\mathrm{C}) .{ }^{*} \mathrm{P}<0.05$ vs. control group; ${ }^{* * *} \mathrm{P}<0.01$ vs. niclosamide or $\mathrm{DDP}$ group. Nic, niclosamide; FITC, fluorescein isothiocyanate.

Niclosamide sensitizes A549/DDP cells to DDP by downregulating LRP and c-myc. To further document the underlying mechanisms by which niclosamide enhanced the inhibitory effect of DDP in A549/DDP cells, western blotting was used to detect the impact of niclosamide on DDP-resistant associated proteins. Initially, the basic expression levels of LRP and c-myc proteins were evaluated in A549 and A549/DDP cells. The expression levels of LRP and c-myc proteins in A549/DDP cells were significantly higher than those of the A549 cells (Fig. 6A). Subsequently, the changes of LRP and c-myc protein expression levels were investigated after treatment with niclosamide and/or DDP in A549/DDP cells. Following treatment with $1.0 \mu \mathrm{M}$ niclosamide alone, A549/DDP cells demonstrated downregulation of LRP and c-myc protein expression levels, while DDP alone exerted no effect on LRP and c-myc protein expression levels. However, upon the combination treatment of niclosamide and DDP, the expression levels of the two proteins were significantly decreased compared with the controls (Fig. 6B). Due to the roles of LRP and c-myc protein on DDP resistance, it was inferred that niclosamide may enhance the 
A

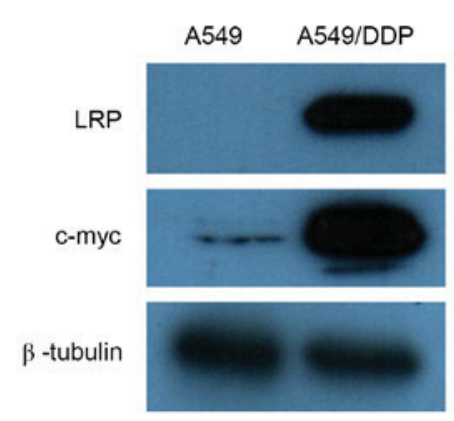

B
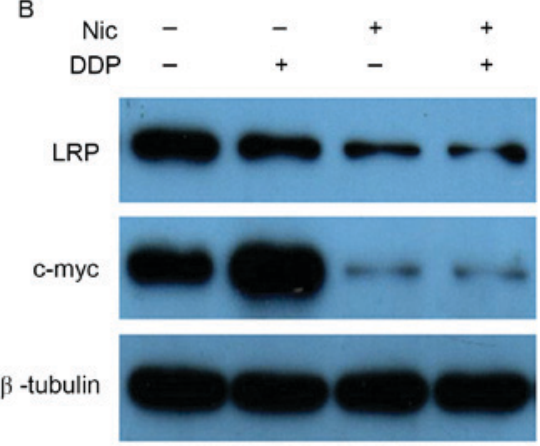

Figure 6. Niclosamide markedly suppressed the expression levels of LRP and c-myc proteins in A549/DDP cells. (A) Basic protein expression levels of LRP and c-myc in A549 and A549/DDP cells. (B) Cells were treated with niclosamide or DDP alone or niclosamide combined with DDP for 24 h. The expression levels of c-myc and LRP proteins were determined by western blot analysis and the representative blots are shown. Nic, niclosamide; DDP, cisplatin; LRP, lung resistance-related protein.

cytotoxic effect of DDP on A549/DDP cells by downregulating the expression level of c-myc protein.

\section{Discussion}

DDP treatment often results in the development of chemoresistance, leading to therapeutic failure (21). Establishing drugs that may overcome DDP resistance is a promising strategy for improving the therapeutic effects of lung cancer treatment. However, drug development, from the initial lead discovery to the final medication, is an expensive and lengthy process (22). By contrast, identifying novel indications for old drugs is considerably faster and more economical than inventing a novel drug altogether, as existing drugs have known pharmacokinetics and safety profiles, and have often been approved for human use (23). In the present study, niclosamide markedly suppressed the proliferation of cisplatin-resistant human A549/DDP lung cancer cells in vitro (Fig. 2). Furthermore, the current study demonstrated that niclosamide in combination with DDP resulted in a synergistic effect in A549/DDP cells (Fig. 3).

Previous studies have reported that niclosamide exhibited synergistic effects when combined with chemotherapeutic agents, oxaliplatin (24), cytarabine, etoposide, daunorubicin and temozolomide (25), and DDP (17). Additionally, niclosamide reversed the resistance of human head and neck cancer cells, and non-small cell lung cancer cells to erlotinib (16,26). Similarly, Liu et al (17) identified that niclosamide alone or in combination with DDP significantly inhibited MDA-MB-231/CS and MDA-MB-231/CR cell proliferation in vitro. Therefore, niclosamide reduces the proliferation of cisplatin-resistant lung cancer cells, indicating that niclosamide may serve as a novel therapeutic strategy, either alone or in combination with DDP, for lung cancer treatment, particularly those resistant to DDP.

The development of DDP resistance arises due to changes in the biochemical pharmacology of DDP. To elucidate whether niclosamide enhances the antitumor effect in A549/DDP cells, the expression levels of LRP and c-myc proteins were examined, and found to be associated with DDP-resistance. Notably, LRP and c-myc were significantly overexpressed in A549/DDP cells compared with A549 cells, and niclosamide reduced the expression levels of LRP and c-myc proteins (Fig. 6). LRP is the predominant human vault protein (27). It reduces the drug concentration in the nucleus and decreases the drug effect on DNA targets (28). A previous study demonstrated that vaults, including LRP, are overexpressed in multidrug-resistant cancer cell lines (29). Consistently, the level of LRP expression is significantly higher in cisplatin-resistant A549/DDP cells than that in parental A549 cells. Furthermore, clinical studies have reported that LRP expression levels predict drug resistance and poor outcome in various types of cancer $(30,31)$. LRP was identified as an independent prognostic factor for overall survival in advanced NSCLC treated with DDP-based chemotherapy (32-34).

C-myc is an important proto-oncogene associated with tumor occurrence and development; its abnormal expression is significant in promoting cell division and proliferation (35). C-myc has been demonstrated to function in numerous cellular processes, including cell proliferation, differentiation and transformation. In addition, c-myc influences cellular sensitivity to DDP (36). Analysis of a panel of ovarian cancer cell lines demonstrated that c-myc protein expression levels were higher in cisplatin-resistant cells when compared with their cisplatin-resistant counterparts. Furthermore, silencing of c-myc by siRNA significantly reduced the tumor growth of cisplatin-resistant cell xenografts (37). Xie et al (38) demonstrated that c-myc was important in regulating DDP resistance in A549/DDP lung cancer cells. Consequently, the current data indicates that niclosamide may enhance the antitumor effect of DDP via suppression of LRP and c-myc proteins, and niclosamide may be a potentially useful therapeutic agent for the treatment of cisplatin-resistant human lung cancer.

On the basis of our findings, combined treatment with niclosamide and DDP may represent a novel and effective strategy for treatment of NSCLC, including for those patients who have already developed resistance to platinum-based therapy. An in vivo animal model would assist in further investigating the efficacy prior to clinical assessment.

\section{Acknowledgements}

The present study was supported by funding from the National Natural Science Foundation of China (grant no. 81201736), Natural Science Foundation of Guangdong Province, China (grant no. 2015A030310460), The Research Fund of Guangdong Medical University (grant no. 2X14031). 


\section{References}

1. Jemal A, Siegel R, Ward E, Hao Y, Xu J and Thun MJ: Cancer statistics, 2009. CA Cancer J Clin 59: 225-249, 2009.

2. Novello S, Barlesi F, Califano R, Cufer T, Ekman S, Levra MG, Kerr K, Popat S, Reck M, Senan S, et al: Metastatic non-small-cell lung cancer: ESMO clinical practice guidelines for diagnosis, treatment and follow-up. Ann Oncol 27 (suppl 5): v1-v27, 2016.

3. Crinò L, Weder W, van Meerbeeck J and Felip E; ESMO Guidelines Working Group: Early stage and locally advanced (non-metastatic) non-small-cell lung cancer: ESMO clinical practice guidelines for diagnosis, treatment and follow-up. Ann Oncol 21 (Suppl 5): v103-v115, 2010.

4. Shi Y, Au JS, Thongprasert S, Srinivasan S, Tsai CM, Khoa MT, Heeroma K, Itoh Y, Cornelio G and Yang PC: A prospective, molecular epidemiology study of EGFR mutations in Asian patients with advanced non-small-cell lung cancer of adenocarcinoma histology (PIONEER). J Thorac Oncol 9: 154-162, 2014.

5. Schuette WH, Gröschel A, Sebastian M, Andreas S, Müller T, Schneller F, Guetz S, Eschbach C, Bohnet S, Leschinger MI and Reck M: A randomized phase II study of pemetrexed in combination with cisplatin or carboplatin as first-line therapy for patients with locally advanced or metastatic non-small-cell lung cancer. Clin Lung Cancer 14: 215-223, 2013.

6. Fennell DA, Summers Y, Cadranel J, Benepal T, Christoph DC, Lal R, Das M, Maxwell F, Visseren-Grul C and Ferry D: Cisplatin in the modern era: The backbone of first-line chemotherapy for non-small cell lung cancer. Cancer Treat Rev 44: 42-50, 2016.

7. Lo Iacono M, Monica V, Vavalà T, Gisabella M, Saviozzi S, Bracco E, Novello S, Papotti $M$ and Scagliotti GV: ATF2 contributes to cisplatin resistance in non-small cell lung cancer and celastrol induces cisplatin resensitization through inhibition of JNK/ATF2 pathway. Int J Cancer 136: 2598-2609, 2015.

8. Zhang F, Duan S, Tsai Y, Keng PC, Chen Y, Lee SO and Chen Y: Cisplatin treatment increases stemness through upregulation of hypoxia-inducible factors by interleukin-6 in non-small cell lung cancer. Cancer Sci 107: 746-754, 2016.

9. Al-Hadiya BM: Niclosamide: Comprehensive profile. Profiles Drug Subst Excip Relat Methodol 32: 67-96, 2005.

10. Al-Gareeb AI, Aljubory KD and Alkuraishy HM: Niclosamide as an anti-obesity drug: An experimental study. Eat Weight Disord 22: 339-344, 2017

11. Chowdhury MK, Turner N, Bentley NL, Das A, Wu LE, Richani D, Bustamante S, Gilchrist RB, Morris MJ, Shepherd PR and Smith GC: Niclosamide reduces glucagon sensitivity via hepatic PKA inhibition in obese mice: Implications for glucose metabolism improvements in type 2 diabetes. Sci Rep 7: 40159, 2017.

12. Huang L, Yang M, Yuan Y, Li X and Kuang E: Niclosamide inhibits lytic replication of Epstein-Barr virus by disrupting mTOR activation. Antiviral Res 138: 68-78, 2017.

13. Wang YM, Lu JW, Lin CC, Chin YF, Wu TY, Lin LI, Lai ZZ, Kuo SC and Ho YJ: Antiviral activities of niclosamide and nitazoxanide against chikungunya virus entry and transmission. Antiviral Res 135: 81-90, 2016.

14. Morin F, Kavian N, Nicco C, Cerles O, Chéreau C and Batteux F: Niclosamide prevents systemic sclerosis in a reactive oxygen species-induced mouse model. J Immunol 197: 3018-3028, 2016.

15. Li Y, Li PK, Roberts MJ, Arend RC, Samant RS and Buchsbaum DJ: Multi-targeted therapy of cancer by niclosamide: A new application for an old drug. Cancer Lett 349: 8-14, 2014.

16. Li R, Hu Z, Sun SY, Chen ZG, Owonikoko TK, Sica GL, Ramalingam SS, Curran WJ, Khuri FR and Deng X: Niclosamide overcomes acquired resistance to erlotinib through suppression of STAT3 in non-small cell lung cancer. Mol Cancer Ther 12: 2200-2212, 2013.

17. Liu J, Chen X, Ward T, Pegram M and Shen K: Combined niclosamide with cisplatin inhibits epithelial-mesenchymal transition and tumor growth in cisplatin-resistant triple-negative breast cancer. Tumour Biol 37: 9825-9835, 2016.

18. Klimaszewska-Wisniewska A, Halas-Wisniewska M, Tadrowski T, Gagat M, Grzanka D and Grzanka A: Paclitaxel and the dietary flavonoid fisetin: A synergistic combination that induces mitotic catastrophe and autophagic cell death in A549 non-small cell lung cancer cells. Cancer Cell Int 16: 10, 2016.

19. Kang MH, Moon SU, Sung JH, Kim JW, Lee KW, Lee HS, Lee JS and Kim JH: Antitumor activity of HM781-36B, alone or in combination with chemotherapeutic agents, in colorectal cancer cells. Cancer Res Treat 48: 355-364, 2016.
20. Zhang W, Zhou H, Yu Y, Li J, Li H, Jiang D, Chen Z, Yang D, $\mathrm{Xu} \mathrm{Z}$ and $\mathrm{Yu} \mathrm{Z}$ : Combination of gambogic acid with cisplatin enhances the antitumor effects on cisplatin-resistant lung cancer cells by downregulating MRP2 and LRP expression. Onco Targets Ther 9: 3359-3368, 2016.

21. Galluzzi L, Vitale I, Michels J, Brenner C, Szabadkai G, Harel-Bellan A, Castedo M and Kroemer G: Systems biology of cisplatin resistance: Past, present and future. Cell Death Dis 5: e1257, 2014

22. Tessari M, Pilla M, Andreoli M, Hutcheson DM and Heidbreder CA: Antagonism at metabotropic glutamate 5 receptors inhibits nicotine- and cocaine-taking behaviours and prevents nicotine-triggered relapse to nicotine-seeking. Eur J Pharmacol 499: 121-133, 2004.

23. Chong CR and Sullivan DJ Jr: New uses for old drugs. Nature 448 645-646, 2007.

24. Osada T, Chen M, Yang XY, Spasojevic I, Vandeusen JB, Hsu D, Clary BM, Clay TM, Chen W, Morse MA and Lyerly HK: Antihelminth compound niclosamide downregulatesWnt signaling and elicits antitumor responses in tumors with activating APC mutations. Cancer Res 71: 4172-4182, 2011.

25. Jin Y, Lu Z, Ding K, Li J, Du X, Chen C, Sun X, Wu Y, Zhou J and Pan J: Antineoplastic mechanisms of niclosamide in acute myelogenous leukemia stem cells: Inactivation of the NF-kappaB pathway and generation of reactive oxygen species. Cancer Res 70: 2516-2527, 2010.

26. Li R, You S, HuZ, Chen ZG, Sica GL, KhuriFR, Curran WJ, Shin DM and Deng X: Inhibition of STAT3 by niclosamide synergizes with erlotinib against head and neck cancer. PLos One 8: e74670, 2013.

27. Scheffer GL, Wijngaard PL, Flens MJ, Izquierdo MA, Slovak ML, Pinedo HM, Meijer CJ, Clevers HC and Scheper RJ: The drug resistance-related protein LRP is the human major vault protein. Nat Med 1: 578-582, 1995.

28. Filipits M, Pohl G, Stranzl T, Suchomel RW, Scheper RJ, Jäger U, Geissler K, Lechner K and Pirker R: Expression of the lung resistance protein predicts poor outcome in de novo acute myeloid leukemia. Blood 91: 1508-1513, 1998.

29. Dalton WS and Scheper RJ: Lung resistance-related protein: Determining its role in multidrug resistance. J Natl Cancer Inst 91: 1604-1605, 1999.

30. Kerr EH, Frederick PJ, Egger ME, Stockard CR, Sellers J, DellaManna D, Oelschlager DK, Amm HM, Eltoum IE, Straughn JM, et al: Lung resistance-related protein (LRP) expression in malignant ascitic cells as a prognostic marker for advanced ovarian serous carcinoma. Ann Surg Oncol 20: 3059-3065, 2013.

31. Tsuji K, Wang YH, Takanashi M, Odajima T, Lee GA, Sugimori H and Motoji T: Overexpression of lung resistance-related protein and P-glycoprotein and response to induction chemotherapy in acute myelogenous leukemia. Hematol Rep 4: e18, 2012.

32. Li J, Li ZN, Du YJ, Li XQ, Bao QL and Chen P: Expression of MRP1, BCRP, LRP, and ERCC1 in advanced non-small-cell lung cancer: Correlation with response to chemotherapy and survival. Clin Lung Cancer 10: 414-421, 2009.

33. Li J, Li ZN, Yu LC, Bao QL, Wu JR, Shi SB and Li XQ: Association of expression of MRP1, BCRP, LRP and ERCC1 with outcome of patients with locally advanced non-small cell lung cancer who received neoadjuvant chemotherapy. Lung Cancer 69: 116-122, 2010.

34. Huang W, Mao Y, Zhan Y, Huang J, Wang X, Luo P, Li LI, Mo D, Liu Q, Xu H and Huang C: Prognostic implications of survivin and lung resistance protein in advanced non-small cell lung cancer treated with platinum-based chemotherapy. Oncol Lett 11: 723-730, 2016.

35. Biliran H Jr, Banerjee S, Thakur A, Sarkar FH, Bollig A, Ahmed F, Wu J, Sun Y and Liao JD: c-Myc-induced chemosensitization is mediated by suppression of cyclin D1 expression and nuclear factor-kappa B activity in pancreatic cancer cells. Clin Cancer Res 13: 2811-2821, 2007.

36. Torigoe T, Izumi H, Ishiguchi H, Yoshida Y, Tanabe M, Yoshida T, Igarashi T, Niina I, Wakasugi T, Imaizumi T, et al: Cisplatin resistance and transcription factors. Curr Med Chem Anticancer Agents 5: 15-27, 2005.

37. Reyes-González JM, Armaiz-Peña GN, Mangala LS, Valiyeva F, Ivan C, Pradeep S, Echevarría-Vargas IM, Rivera-Reyes A, Sood AK and Vivas-Mejía PE: Targeting c-MYC in platinum-resistant ovarian cancer. Mol Cancer Ther 14: 2260-2269, 2015.

38. Xie C, Pan Y, Hao F, Gao Y, Liu Z, Zhang X, Xie L, Jiang G, Li Q and Wang E: C-Myc participates in $\beta$-catenin-mediated drug resistance in A549/DDP lung adenocarcinoma cells. APMIS 122: 1251-1258, 2014.

This work is licensed under a Creative Commons Attribution-NonCommercial-NoDerivatives 4.0 International (CC BY-NC-ND 4.0) License. 